\title{
Analysis of seismic behavior for transform structures
}

\author{
Xiaomig Chen ${ }^{1, a}$, Jin Duan ${ }^{1}$, Yungui Li ${ }^{1}$, Jianyun Sun ${ }^{1}$ \\ ${ }^{1}$ China state construction technical center, Beijing, China \\ aHanee@126.com
}

\begin{abstract}
Keywords: Seismic behavior, transform structure, elastic-plastic, ABAQUS
Abstract. Frame-supported shear wall structures are designed with more limitations than shear wall structures and frame-tube structures because of the abrupt change of vertical stiffness. The transform members are proposed to be designed with enough stiffness to ensure those stories below the transform floor being damaged latter than the upper part. The seismic performance was researched by using numerical method for such a structure. Numerical results show that this kind of structure would be damaged as we expected if stiffness has been controlled reasonably, and it can exhibit good seismic performances either, though this structural form is not suggested by Chinese codes.
\end{abstract}

\section{Introduction}

When shear walls cannot be designed with foundation at their bottom, the loads carried by these walls have to be transferred to some horizontal transform members, this kind of structures is called transform structure, and the floor with those horizontal transform members is called transform floor. Compared with truss transforming and thick plate transforming, beam transforming is the most widely used form, which is also called frame-supported shear wall structure [1].

The seismic performance of structures would be decreased because of the discontinuous vertical stiffness, therefore, transform structures are forbidden to be designed for those regions of fortification intensity 9, and for the other fortification intensities, the upper limit of structural height should be designed lower than shear wall structures about 30 meters.

For improving the seismic performance, professor $\mathrm{Xu}$ [2] advised that the reasonable failure mode for transform structures is that the upper part should dissipate seismic energy as much as possible to avoid the bottom being damaged seriously, the similar failure mode was also proposed by structural tests by Liu [3].

Aimed at this performance objective, enough continuous shear walls are necessary at first, and the stiffness of upper structure also can be weakened as the substitutive approach. About the designing details, professor $\mathrm{Fu}[4]$ has given more advises.

Except the lateral stiffness, the ratio of drift angle about the transform floor should be controlled either as advised by professor Wang [5]. Compared with stiffness ratio, the ratio of drift angle is more sensitive to structural discontinuity, it can amplify the ratio of stiffness about $9 \%-22 \%$.

A structure with high transform floor was analyzed by using numerical method for researching the seismic performance with seismic waves loaded at the base in this paper. Multi-level of peak ground acceleration (PGA) was considered so as to give advices for seismic design.

\section{Structural model}

A 34-floor structure shown in Filg.1 was designed for 8-intensity of seismic fortification, and the sixth floor was designed as transform floor. Stiffness ratio of the lower part to upper part of transform floor are 1.54 and 1.32 for $x$ and $y$ directions respectively. The seismic wave loaded at the base is also shown in Fig. 1

According to the Chinese code, except the structure loaded with seismic wave of PGA equal to $400 \mathrm{gal}$ was analyzed, medium earthquake of 200gal and rare earthquake of 8.5-intensity (510gal) are also loaded at the structural base for comparison[6]. 

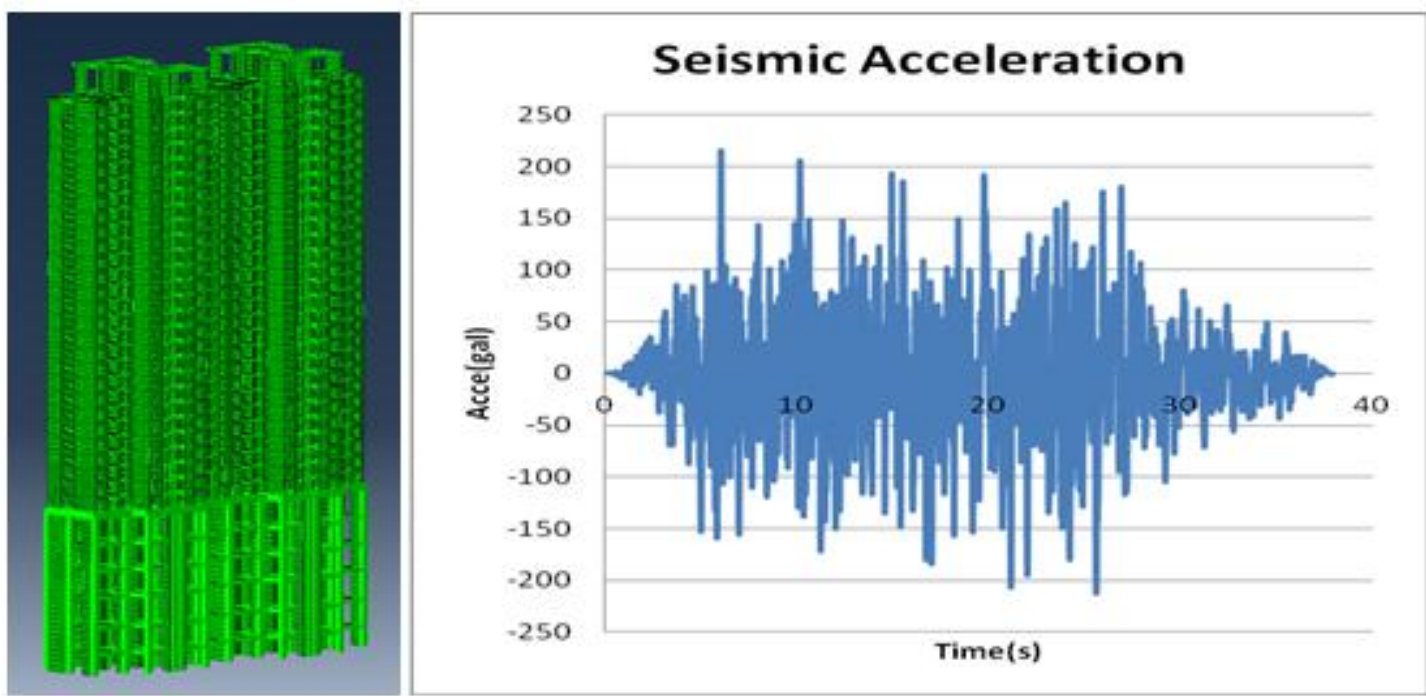

Fig.1 Structural model and seismic wave

\section{Drift angle of floors}

Envelope of floor drift angle is the most important criterion used to keep the structure free from collapse under earthquake. The envelopes of drift angle for different PGA are shown in Fig.2.

According to the envelopes shown in Fig.2, no significant damage happened under 200gal PGA. Under expected rare earthquake of $400 \mathrm{gal}$ PGA, the max drift angle is $1 / 139$ at $12^{\text {th }}$ floor, which is still less than $1 / 120$ (limited value of Chinese codes). Under 8.5-intensity (510gal), it can be seen that those stories near the $12^{\text {th }}$ floor are damaged seriously.

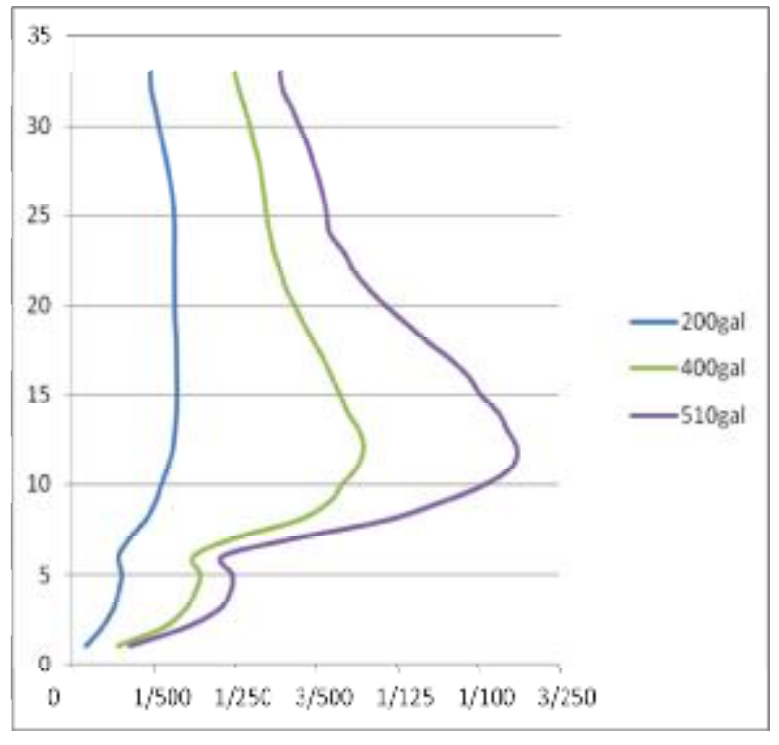

Fig.2 Envelopes of drift angle

\section{Shear force carried by vertical members}

According to the regulations of Chinese codes, frame columns below transform floor should be designed with enough shear capacity to ensure them to be damaged latter than shear walls. The max shear forces carried by frame columns and the total shear forces of the floor are both shown in Fig.3 to Fig. 8 together with the relative ratios.

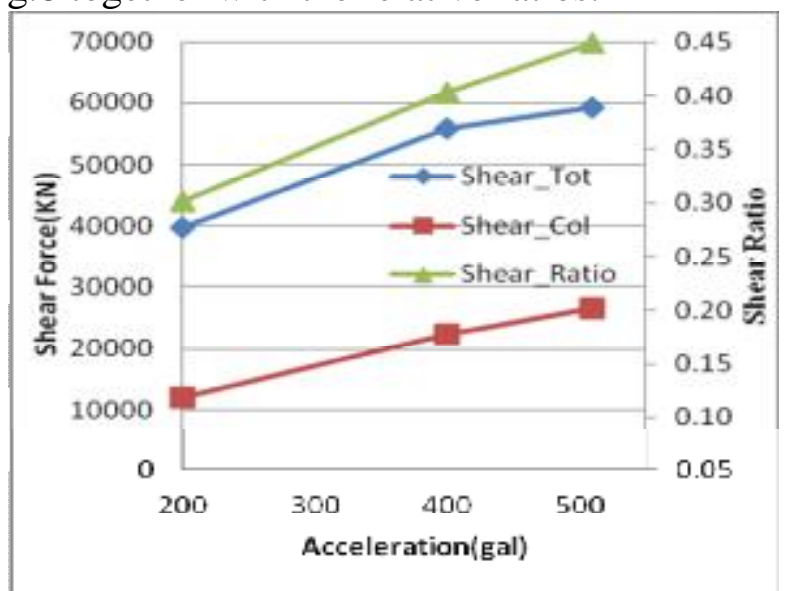

Fig. $31^{\text {st }}$ floor (Base)

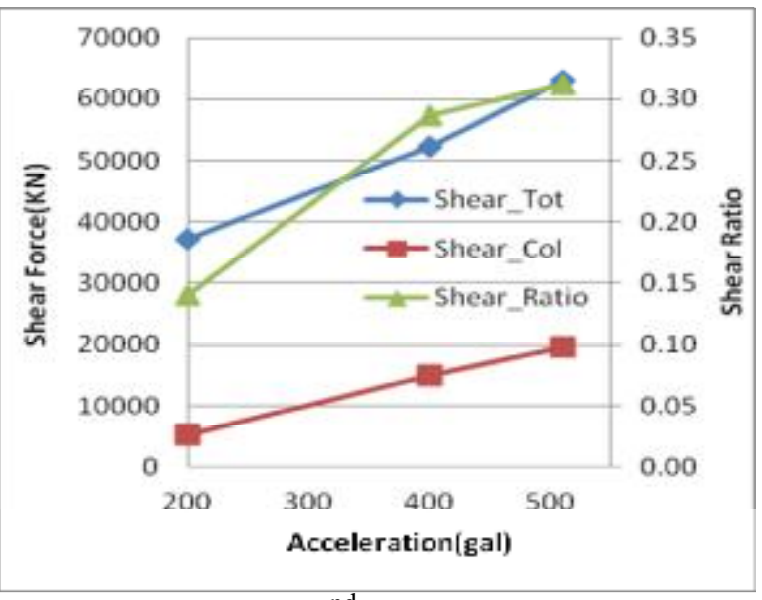

Fig. $42^{\text {nd }}$ floor 


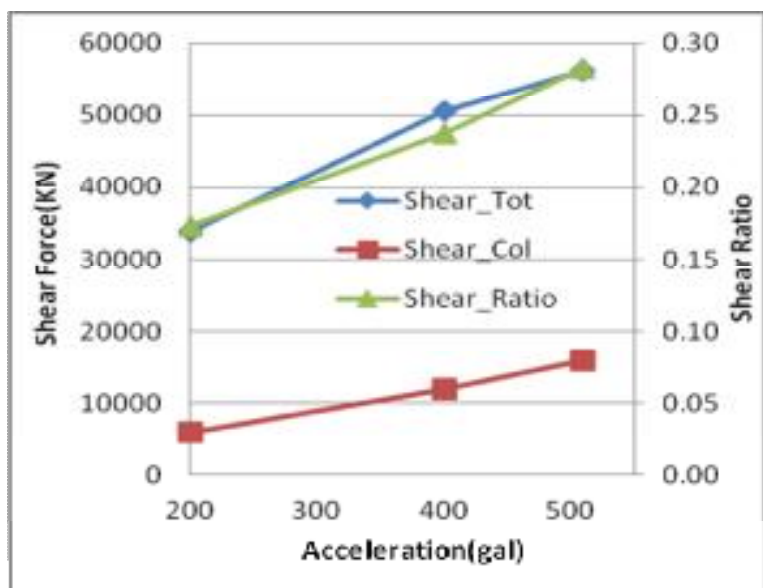

Fig. $53^{\text {rd }}$ floor

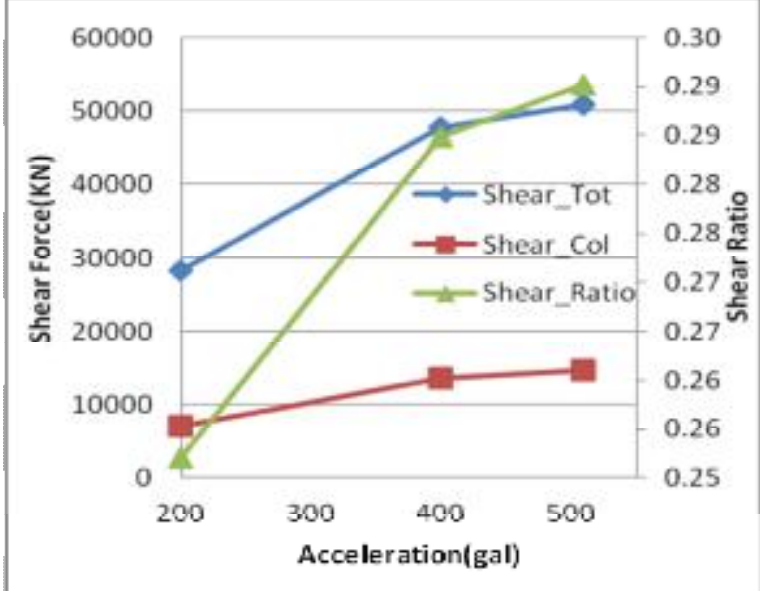

Fig. $75^{\text {th }}$ Floor

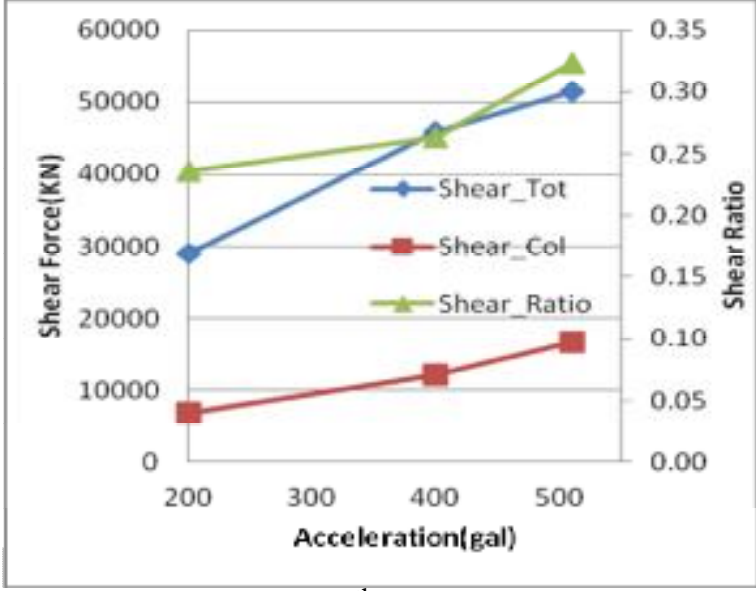

Fig. $64^{\text {th }}$ floor

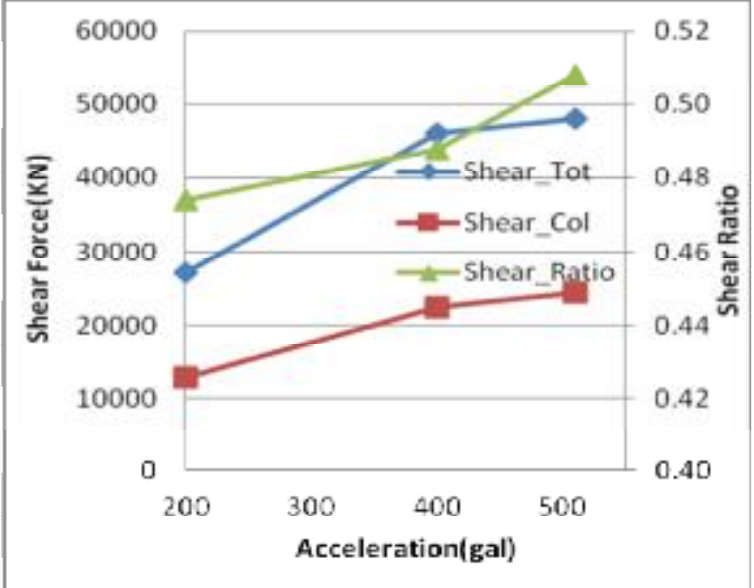

Fig. $86^{\text {th }}$ floor (transform floor)

These results show that the frame columns in transform floor carried about $45 \%$ of the total vertical shear force, which is even bigger than the ratio of $24 \%$ at the base, thus those frames designed for supporting upper walls would be the most critical members. To avoid these members to be damaged, the whole structure would exhibit better seismic performance.

\section{Compressive damage of concrete members}

The compressive damage of shear walls and frameworks are shown in Fig.9 to Fig.11.
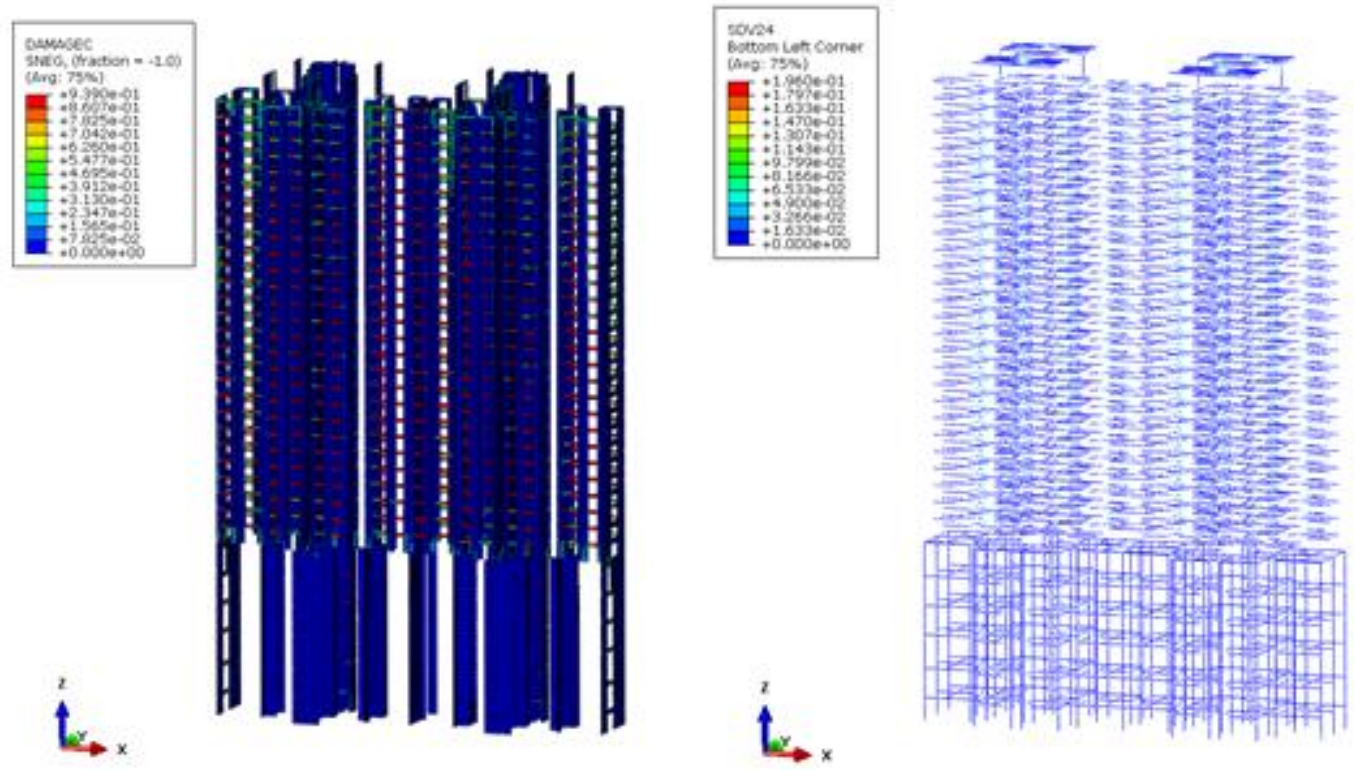

Fig. 9 Compressive damage of 200gal 


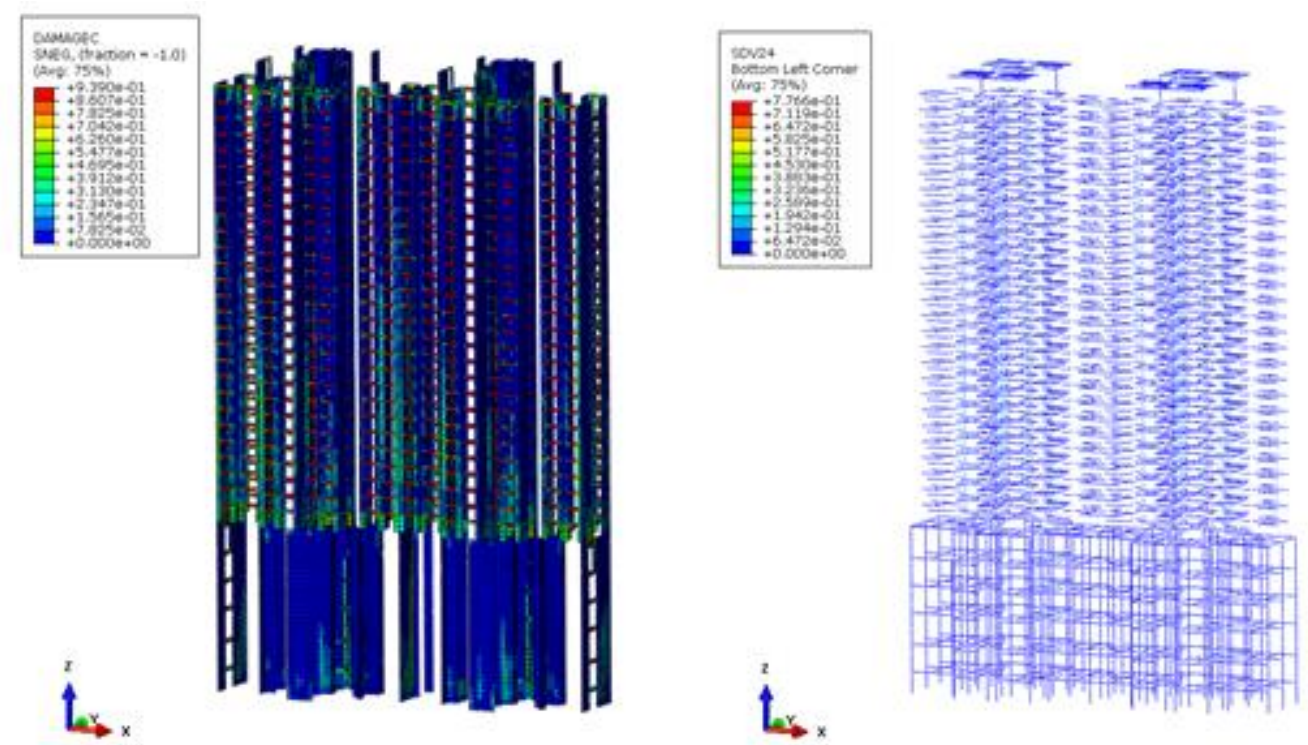

Fig.10 Compressive damage of 400gal
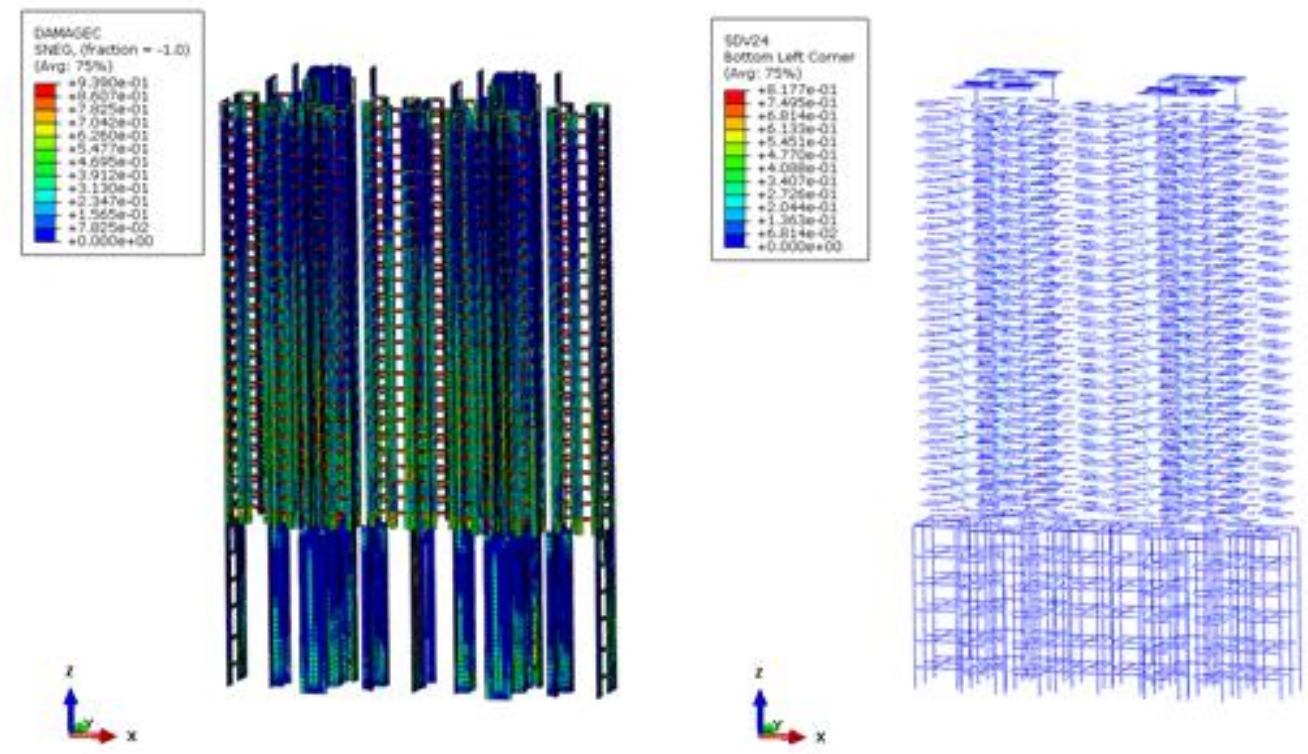

Fig.11 Compressive damage of 510gal

Under 200gal PGA, Most of damaged members are coupling beam, those vertical members could keep free of even slight damage. For 400gal PGA, shear walls over transform floor are also damaged seriously, compression damage of columns is still negligible. Under 510gal PGA, even though shear walls are damaged continuously to structural upper and shear walls below transform floor are also damaged from the bottom, only few columns in transform floor are damaged slightly.

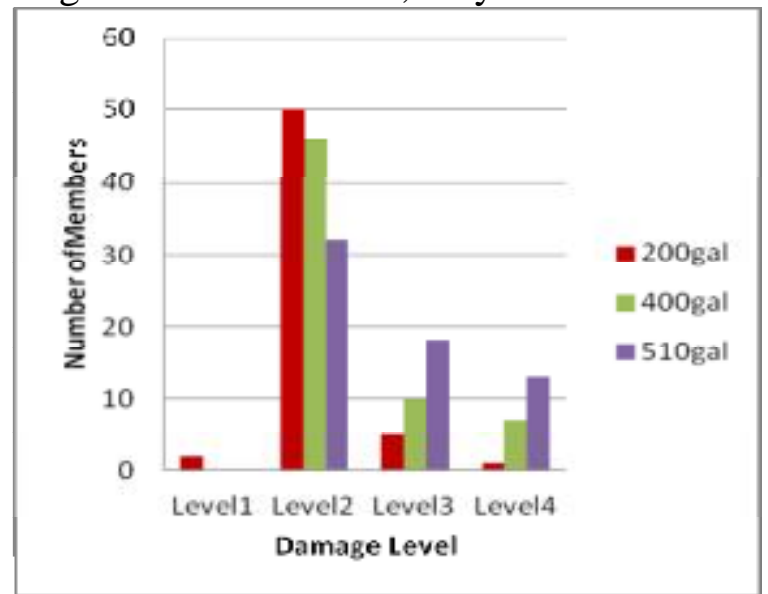

Fig.12 Damage of shear walls of $6^{\text {th }}$ floor

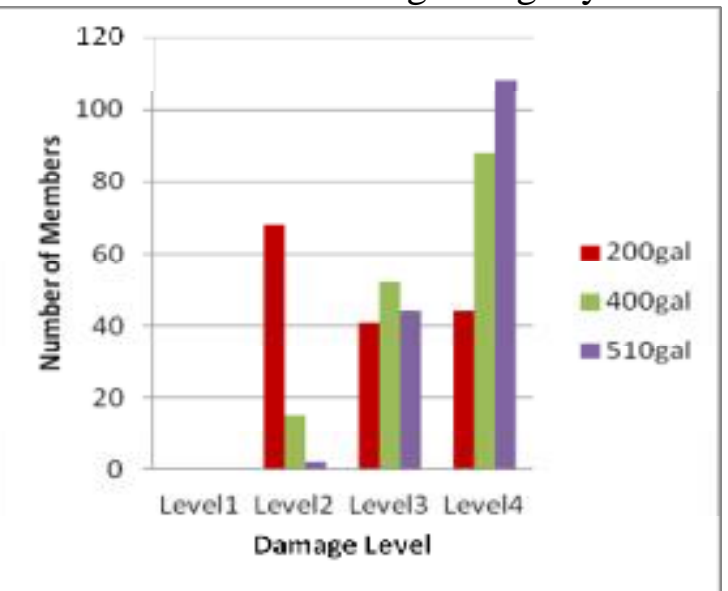

Fig.13 Damage of shear walls of $7^{\text {th }}$ floor 
By defining four damage levels according to the compressive damage[1], the statistic of shear walls for the 6th and 7th floor are shown in Fig.12 and Fig.13 respectively. As shown in Fig.12 and Fig.13, shear walls in 7 th floor are damaged more seriously than those in the transform floor.

\section{Conclusions}

For frame-supported shear wall structure, the transform members should be designed with enough lateral stiffness to make sure that those stories below the transform floor should be damaged latter than the upper part. The seismic performance of a transform structure was researched by using numerical method. Although this kind of structural form is not suggested to be used by Chinese codes, actually, by using those principles proposed by researchers, numerical results show that the structure would be damaged under our control, and it can exhibit good seismic performances as we expected.

\section{References}

[1] China architecture \& building press. Technical specification for concrete structures of tall building, Beijing, China. (2010)

[2] Xu Peifu, Wang Yayong, Dai Guoying. Discussion on Review of Seismic Fortification of Tall Building with Design Beyond the Code Limits. China Civil Engineering Journal. Vol.37(1):1-6. (2004)

[3] Liu Jianwei. Study of Optimal Failure Mode and Corresponding Control Measures for Frame-Supported Shear Wall Structure. PHD dissertation, Chongqing University.(2011)

[4] Fu Xueyi. Design Proposals of Tall Building Structures with Transfer Stories. Journal of Building Structures. Vol.20(2):28-41. (1999)

[5] Wang Yayong. Application of Ratio of Story Drift Angles Above and Below the Transfer Floor in seismic Design of Tall Building Structure. Building Structure. Vol.37(8):1-4. (2007)

[6] China architecture \& building press. Code for seismic design of buildings. Beijing, China. (2010) 